\title{
Incoherent Scatter Radar Observations of Westward Electric Fields and Plasma Densities in the Auroral Ionosphere, 1
}

\author{
P. M. Banks \\ Radioscience Laboratory, Stanford University, Stanford, California 94305
}

C. L RINO AND V. B. WICKWAR

Stanford Research Institute, Menlo Park, California 94025

\begin{abstract}
This paper reports the results of incoherent scatter radar observations of high-altitude ion drifts and other plasma parameters made February 24, 1972, at Chatanika, Alaska $(L=5.7)$, during a period of magnetic disturbance. For this experiment, conducted between 0909 to 1303 UT (2309 to 0303 AST), the radar line of sight was held fixed in the magnetic meridian plane so that the observed north-south ion drifts could be interpreted in terms of a westward electric field that ranged in magnitude from -10 to $+35 \mathrm{mV} \mathrm{m}^{-1}$. The results confirm many effects found previously through other experimental techniques. Southward ion drifts predominated during the 4-hour observation period. Several times the westward electric field inside large regions of enhanced electron density was substantially smaller than the field outside these regions. In addition, on several occasions these walls or bands of ionization were found to drift southward at about the same speed as the $\mathbf{E}_{\perp} \times \mathbf{B}$ drift in the surrounding plasma. The plasma inside the enhanced region, however, did not share the drift motion but remained relatively stationary with respect to the radar. The present observations of $F_{2}$ layer densities and temperatures indicate an unusual increase in electron density just before the onset of a large substorm. Finally, measurements of the height and peak density of the auroral $E$ layer show significant variations in the intensity and average energy of the electron flux. These variations appear to be related to auroral breakup and a transition to steady precipitation of moderately soft electrons.
\end{abstract}

Measurements of electric fields in the auroral ionosphere have been made by a variety of methods. These include: (1) direct measurements by rocket probes [e.g., Mozer and Bruston, 1967; Aggson, 1969; Potter and Cahill, 1969; Mozer and Fahleson, 1970; Potter, 1970; Fahleson et al., 1971; Kelley et al., 1971a; Choy et al., 1971; Bering et al., 1973], satellite probes [Cauffman and Gurnett, 1971; Heppner, 1972], and balloon-borne double probes [Mozer and Serlin, 1969; Mozer and Manka, 1971; Kelley et al., $1971 b$; Mozer et al., 1973], and (2) indirect measurements through observations of the motions of ionized barium clouds [e.g., Föppl et al., 1968; Wescott et al., 1969, 1970; Haerendel et al., 1969; Haerendel and Lüst, 1970; Fahleson et al., 1971; Heppner et al., 1971; Haerendel, 1972, unpublished manuscript, 1973], by incoherent scatter radar [Doupnik et al., 1972; Banks et al., 1973, manuscript in preparation, 1973], and by satellite-borne ion current probes [Galperin and Ponomarev, 1972], and (3) observation of drift motions of visible aurora [Davis, 1971; Kelley et al., 1971b; Subbarao and Rostoker, 1973].

In two previous studies [Doupnik et al., 1972; Banks et al., 1973] and in a third study whose results are being prepared for publication (Banks et al., 1973) the incoherent seatter radar at Chatanika, Alaska $\left(L=5.7, \Lambda=65.2^{\circ}\right)$, has been used to infer electric fields from ion Doppler shifts in the ionosphere at altitudes greater than $150 \mathrm{~km}$ where the relation $\mathbf{v}_{\perp}=\mathbf{E}_{\perp} \times \mathbf{B} / \boldsymbol{B}^{\mathbf{2}}$ is valid. Owing to the intrinsic limitations of a monostatic radar site, the ion Doppler velocities needed

\footnotetext{
${ }^{1}$ On leave of absence from the University of California at San Diego, La Jolla, California 92037.
}

Copyright (C) 1974 by the American Geophysical Union. to determine $\nabla_{\perp}$ and $\mathbf{E}_{\perp}$ are obtained by consecutive measurements in three separate directions. As a consequence, largescale temporal and spatial filtering effects are introduced into the radar data. With regard to the temporal resolution, the pattern of consecutive measurements permits new ion velocity vectors to be constructed every $10 \mathrm{~min}$, but the overall time required for truly independent velocity vectors is about 30 min. In addition, the individual line of sight ion velocities are obtained from points separated by about $107 \mathrm{~km}$ at 170 $\mathrm{km}$ altitude. Although such smearing is acceptable for many purposes dealing with the gross behavior of diurnal electric fields and ionospheric $E$ region current densities, a finer resolution is essential for investigating electric fields associated with substorms and auroras.

Attempts to improve the space-time resolution of electric field measurements have been made in a recent series of magnetic meridian experiments at Chatanika. By keeping the radar antenna fixed in the magnetic meridian plane at an elevation angle of $45^{\circ}$, the north-south drift speed of ions can be determined at 1-min intervals in range gates that have an effective length of about $45 \mathrm{~km}$. In addition, the electron density can be simultaneously measured along the radar line of sight in 192 overlapping range gates of $10-\mathrm{km}$ width.

Additional meridian plane measurements were made in February and March 1973 and will be reported in a later paper [Rino et al., 1973]. In the present paper, results are given for a similar experiment conducted inadvertently (owing to low temperatures, the radar antenna was kept stationary in the magnetic meridian plane) in the evening hours of February 24, 1972. This period was characterized by a high level of magnetic activity, and the experimental results illustrate a number of important features of auroral 


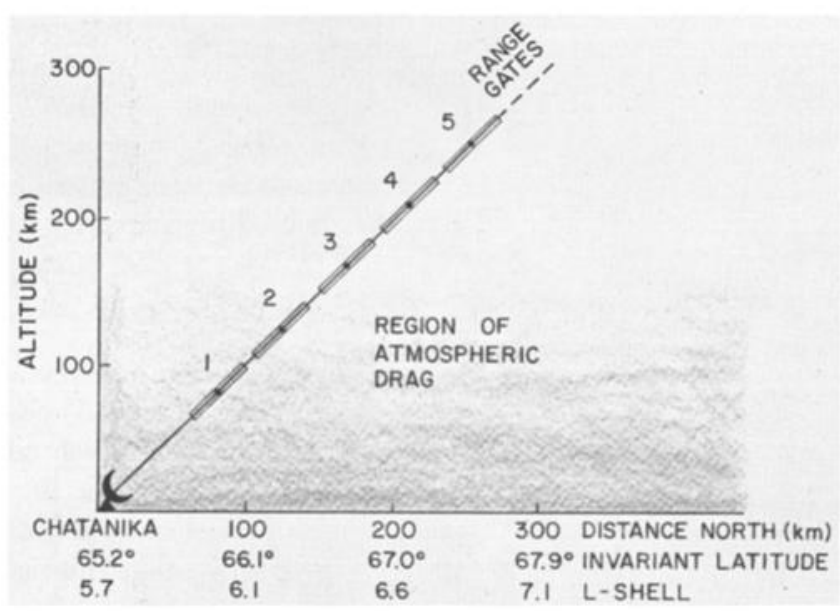

Fig. 1. Schematic view of Chatanika spectral range gates for the experiment of February 24, 1972, in the period 1000$1300 \mathrm{UT}$. Ion velocities from range gate $3(167-\mathrm{km}$ altitude) provided the data needed to compute E-W electric fields.

electric fields and auroral motions. Though we cannot generalize the present results to all conditions, the study provides a unique view of various interrelated auroral phenomena.

The principal results of this study, to be discussed in the following sections, include the following.

1. During the 4 hours of the experiment, southward ion drifts were predominant.

2. There were several times when the westward component of the electric field was small inside extended bands or patches (up to $50 \mathrm{~km}$ wide) of high electron density.

3. These regions of high electron density drifted southward at about the same speed as the $\mathbf{E}_{\perp} \times \mathbf{B}$ drift seen in adjacent regions of relatively low electron density.

4. The southward drift of the ionization enhancements was most strongly evident during the recovery phase of a local midnight sector substorm. However, southward drifts of enhanced ionization regions were also seen several times in the hour before the substorm.

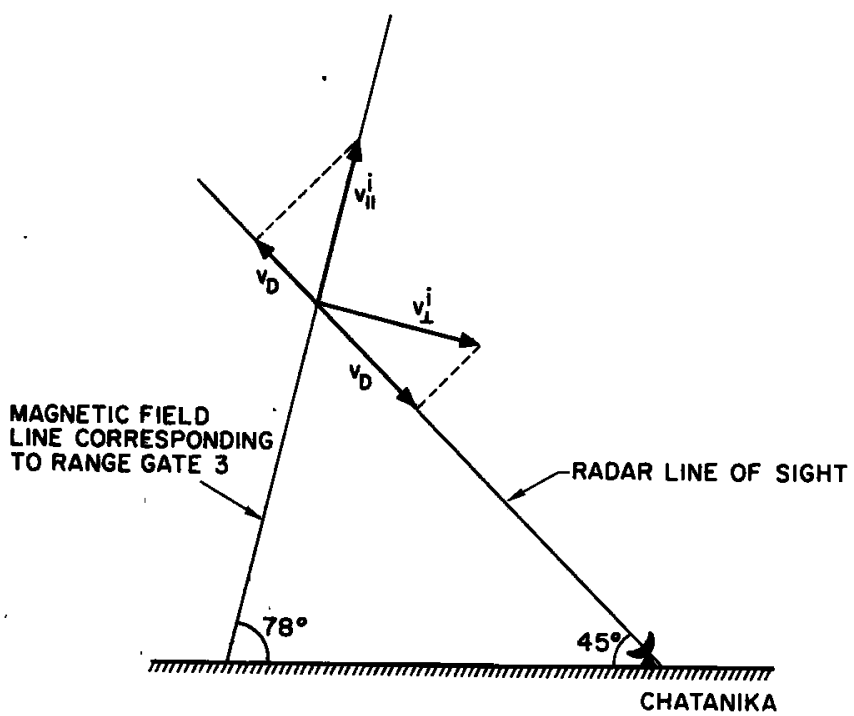

Fig. 2. Measurements of N-S ion velocities reflect ion motions parallel and perpendicular to $B$. Since $F$ region velocities parallel to $B$ are usually much smaller than the perpendicular velocities, the present experiment measures principally $\nabla_{1}^{\iota}$.

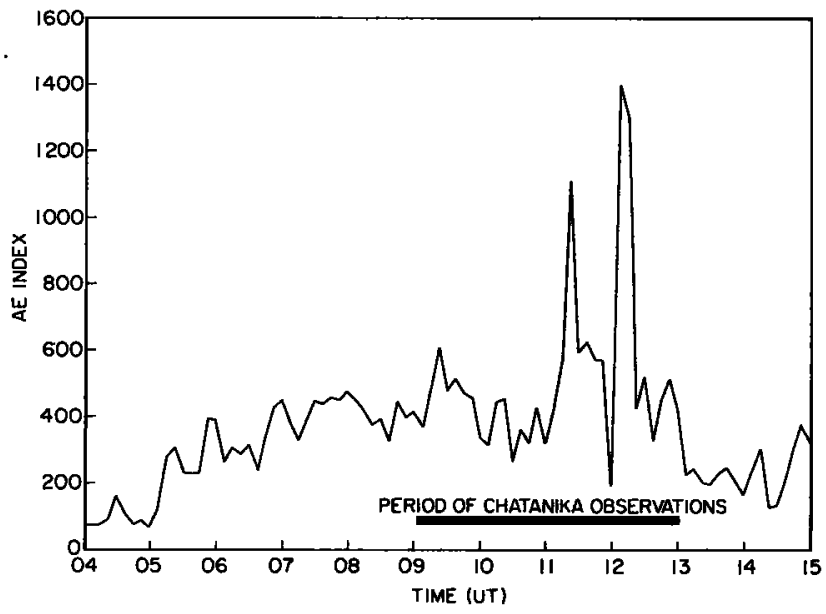

Fig. 3. Auroral electrojet index (AE) for February 24, 1972. Data were provided by the NOAA World Data Center.

5. The largest drifting ionization enhancement could be identified with visible auroral emissions.

6. A very intense $F_{2}$ layer appeared $30 \mathrm{~min}$ before a substorm with a southward drift of $400 \mathrm{~m} \mathrm{sec}-1$, then vanished within $1 \mathrm{~min}$ after substorm onset. Coincident with the removal of the $F_{2}$ layer ionization, an enhanced auroral $E$ layer appeared.

\section{DESCRIPTION OF EXPERIMENT}

The incoherent scatter radar system at Chatanika, Alaska, has been described by Leadabrand et al. [1972] and Baron [1972], while the basic principles of the incoherent scatter method have been reviewed by Evans [1969, 1972]. The radar operates in a monostatic mode at $1290 \mathrm{MHz}$ using two interspersed pulse lengths. A long pulse, lasting $\mathbf{3 2 0}$ $\mu$ sec, is used to determine ion Doppler shift and electron and ion temperatures in eight range gates of about $45 \mathrm{~km}$ effective length which are separated by a distance of 60 $\mathrm{km}$. (Details of the data processing procedures are given by Baron et al. [1970] and Rino [1972], while the results of other experiments using the radar have been reported by Doupnik et al. [1972], Bates et al. [1973], Watt [1973], Brekke et al. [1973], and Banks et al. [1973].) In addition to the long-pulse spectral channel, a short $67-\mu$ sec pulse is used to provide electron density data from 192 overlapping range gates having effective widths of $10 \mathrm{~km}$. For both

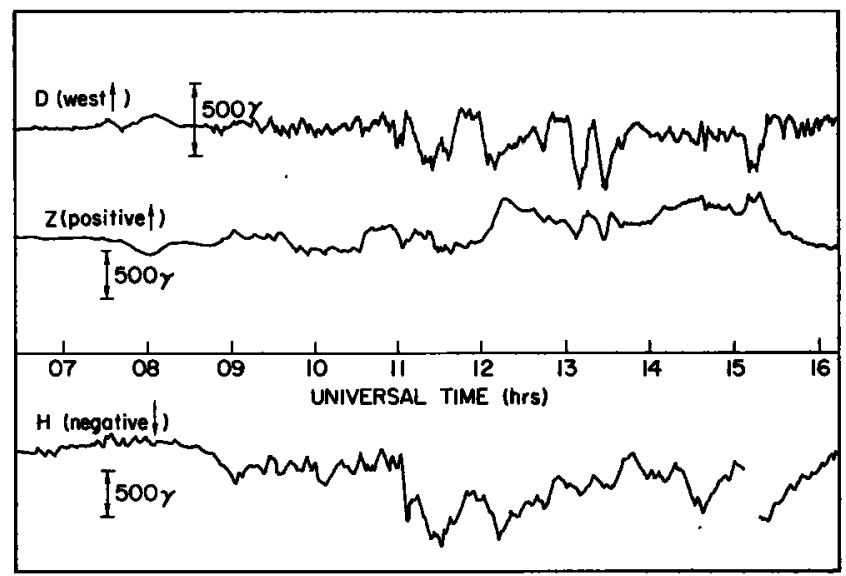

Fig. 4. College magnetogram for February 24, 1972. 

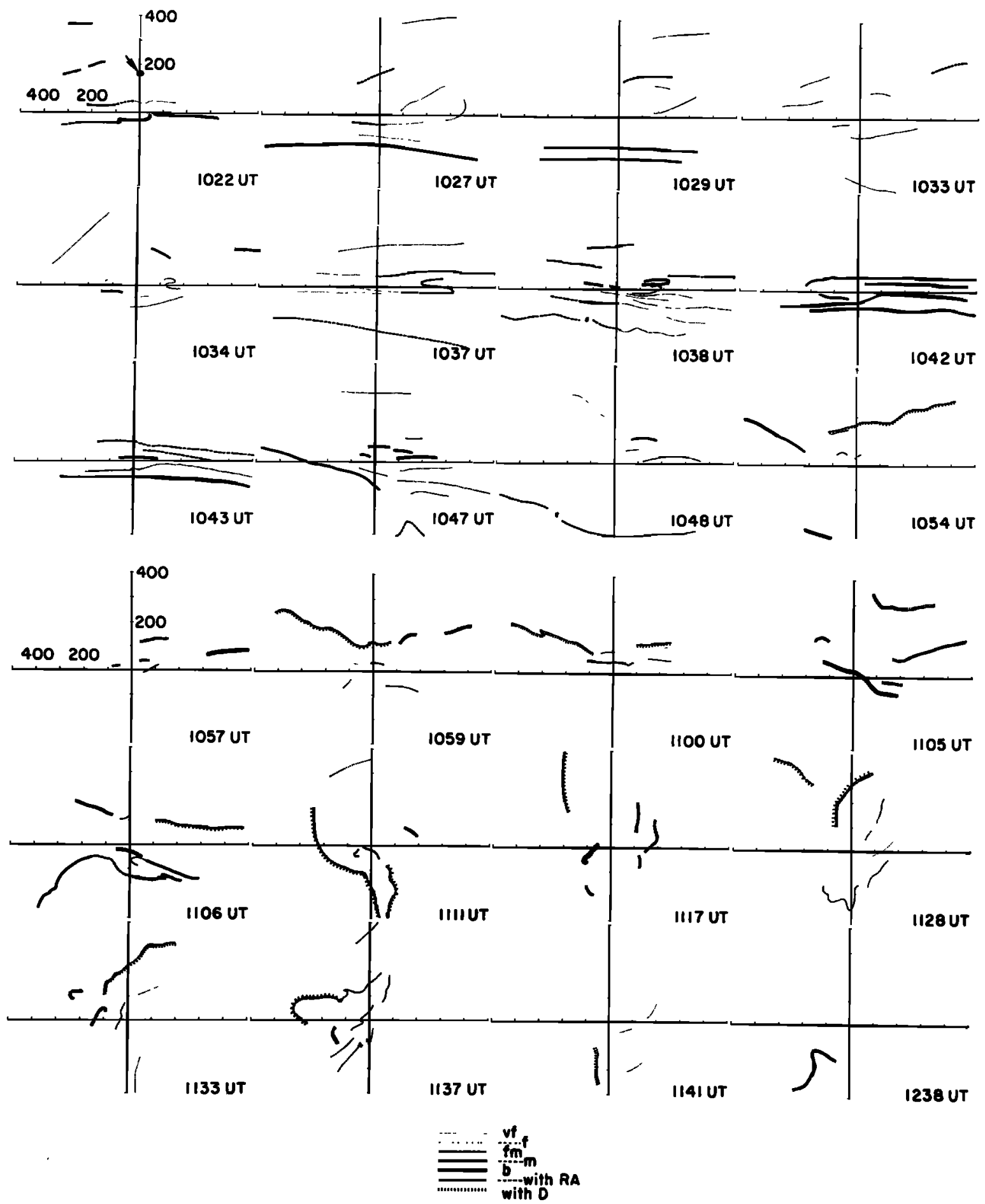

Fig. 5. Auroral maps obtained from 35-mm Chatanika all-sky camera photographs. Directions are geomagnetic, north being at the top, east to the right. The arrow and dot at 1022 UT indicate the center of the radar third range gate. Distances are given in kilometers. Legend: vf, very faint; f, faint; fm, faint to medium; m, medium;
b, bright; RA, with rayed arcs; D, with diffuse arcs.

spectral and density channels the antenna beamwidth gives a probing diameter of $2.1 \mathrm{~km}$ at $200 \mathrm{~km}$ range.

It is difficult to calculate the statistical uncertainty of the radar Doppler shift measurements, but various tests made with injected radio signals of known frequency shift indicate a rms error of $\pm 20 \mathrm{msec}^{-1}$ for a signal to noise ratio greater than about 0.3 and 1-min integration. For this relatively short signal integration period, which is used here (1 $\mathrm{min}$ ), and the typically low plasma densities in the present experiment, signal to noise ratios lower than 0.3 were occasionally encountered, and the velocity resolution with 1-min integration was clearly degraded. Examination of the results, however, indicates that the resolution was probably no worse than $\pm 50 \mathrm{msec}^{-1}$ or an equivalent perpendicular electric field of $\pm 2.5 \mathrm{mV} \mathrm{m}^{-1}$.

The present experiment started at 0909 UT, February 24, 1972, and ended at 1303 UT (local time $=$ UT -9 hours $51 \mathrm{~min}$; corrected geomagnetic time = UT -11 hours $10 \mathrm{~min}$ ). During the experiment the antenna azimuth was kept at $0^{\circ}$ magnetic so that only the north-south compo- 

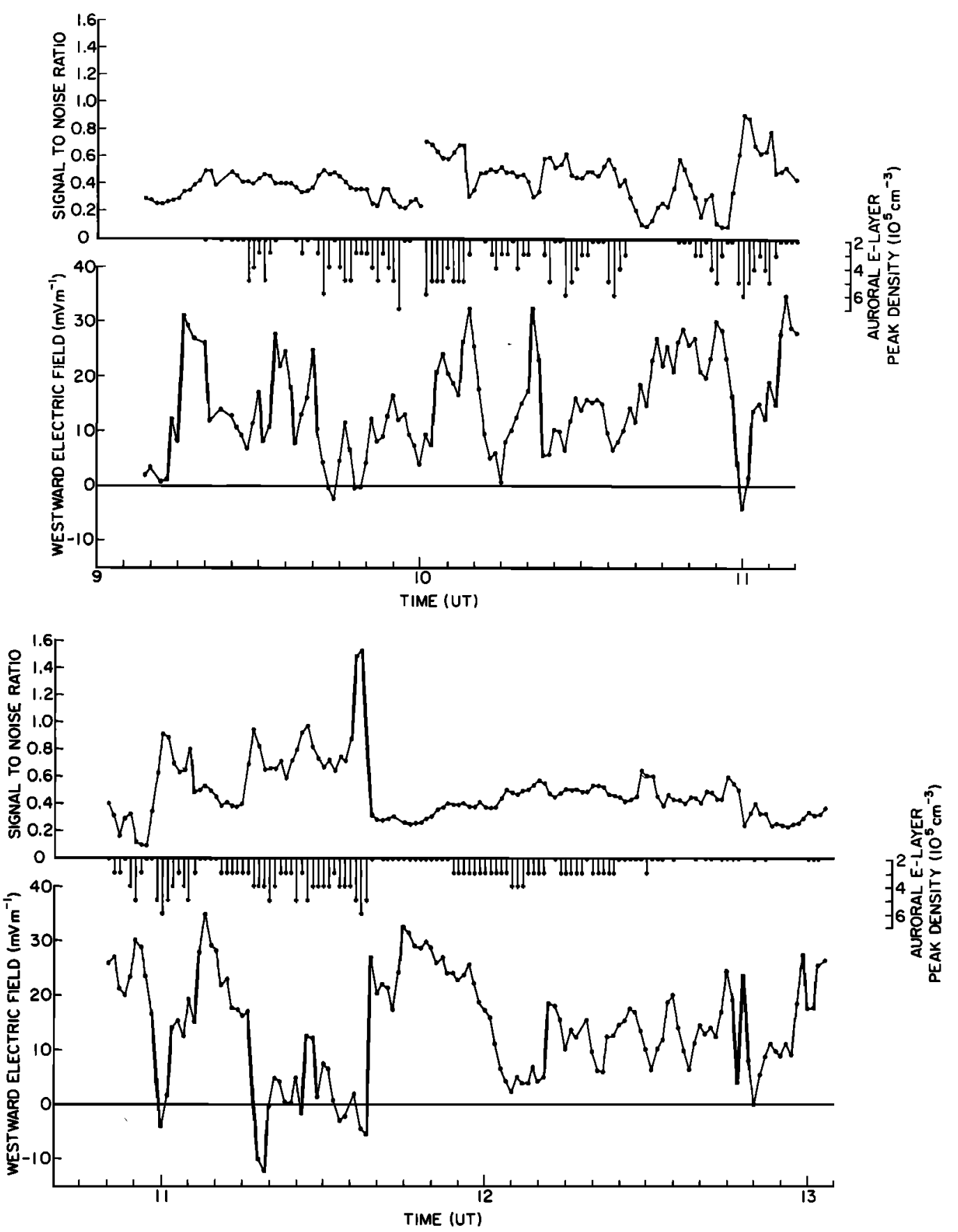

Fig. 6. Values of the westward component of the ionospheric electric field perpendicular to $B$ obtained with 1-min data averages for (top) 0907-1110 UT and (bottom) 1020-1310 UT. The range gate 3 signal to noise ratio is proportional to the spectral channel electron density. The peak density of the auroral $E$ layer is also shown.

nent of ion motions could be observed. For the first hour (0909 UT to $1000 \mathrm{UT}$ ) the antenna elevation angle was $60^{\circ}$ above the horizon. At $1000 \mathrm{UT}$ the elevation angle was changed to $45^{\circ}$ and was kept there for the rest of the experiment. The geometry for the latter part of the experiment is shown in Figure 1.

From previous work [Doupnik et al., 1972; Brekke et al., 1973] it has been found that the effect of atmospheric drag is important below about $150 \mathrm{~km}$ and that the lowest two spectral range gates illustrated in Figure 1 cannot be used to infer ionospheric electric fields. To verify the lack of atmospheric drag, ion velocity data from the range gates at 167 and $209 \mathrm{~km}$ have been compared and found to agree very closely.
It also follows from Figure 1 that the measured ion Doppler shifts can arise from ion motions parallel and perpendicular to the magnetic field B (see Figure 2). For the present geometrical arrangement an ion motion of $100 \mathrm{~m} \mathrm{sec}^{-1}$ parallel to $B$ (and outward) would give a line of sight velocity of $\mathbf{5 4 . 5}$ $\mathrm{m} \mathrm{sec}^{-1}$ away from the radar, whereas a southward ion motion of $100 \mathrm{~m} \mathrm{sec}^{-1}$ perpendicular to $B$ and in the plane of observation would give a line of sight velocity of $83.8 \mathrm{~m} \mathrm{sec}^{-1}$ toward the radar. Previous Chatanika measurements of ion motions in the $F$ region have shown that ion velocities parallel to $B$ as large as $100 \mathrm{~m} \mathrm{sec}^{-1}$ are not common, typical values being on the order of $50 \mathrm{~m} \mathrm{sec}^{-1}$ or less even during high levels of substorm activity [Baron, 1972]. Since the peak $F$ region north-south velocities measured in this experiment were of 
the order of 300 to $600 \mathrm{~m} \mathrm{sec}^{-1}$, we have assumed that the observed ion spectrum Doppler shifts in range gate $3(167-\mathrm{km}$ altitude) correspond to ion drift under the action of an E-W component of the perpendicular electric field whose magnitude follows from the relation $\mathbf{E}_{\perp}=-\nabla_{\perp} \times \mathbf{B}$.

Before the experimental results are presented, two additional details must be discussed. The first is the effective spatial resolution of the spectral channel range gates. As Rino [1972] and Brekke et al. [1973] pointed out, the spectral data are processed through autocorrelation techniques, so that a given velocity estimate encompasses data from a $96-\mathrm{km}$ range spread. However, the measured ion velocity is an average value that involves an effective triangular weighting function, an $R^{-2}$ range dependence, and the range profiles of electron density and ion Doppler shift. These quantities are spatially integrated along the radar line of sight to give the observed Doppler shift in a given range gate. As a consequence, the width and peak response range of a given gate can vary slightly with changes in the range distribution of electron density and ion velocity. For typical $E$ and $F$ region conditions, however, it seems that the effective widths of the spectral gates are about $45 \mathrm{~km}$ (J. R. Doupnik, personal communication, 1973).

The second detail is the short-pulse measurements of electron density. The total power received is proportional to the electron density modified by a range $R^{-a}$ factor and a plasma temperature factor:

$$
n_{e} / n_{e}{ }^{\prime} \cong\left(1+\alpha^{2}\right)\left(1+r+\alpha^{2}\right) / 2
$$

where $r=T_{e} / T$ and $\alpha^{2}$ is the Debye length correction, $\cong 14 T_{e} / n_{e}[$ [Evans, 1969$]$.

Owing to the expense of computation, the electron densities given here do not include the temperature correction factors. As a consequence, the electron densities above about $200 \mathrm{~km}$ are underestimates such that at $300 \mathrm{~km}$ the results could be too small by $50 \%$ if $r=2$. However, this underestimate at high altitudes does not affect the present analysis in any direct way. Further details of the normalization of the electron density data are given by Baron [1972].

\section{Background Geophysical Conditions}

This experiment was conducted during a period of highly disturbed magnetic and auroral conditions. The auroral electrojet index, shown in Figure 3 , indicates that this activity commenced about $0500 \mathrm{UT}$ and reached a peak in the period 1100 to 1230 UT. For reference, the magnetogram obtained at College, Alaska (located $27 \mathrm{~km}$ south of Chatanika), is shown in Figure 4. From these data it is clear that the large midnight sector substorm near College at $1100 \mathrm{UT}$ was not isolated but occurred during a period of sustained magnetic activity that began in the College area at about $0840 \mathrm{UT}$.

Visible aurora were recorded during a portion of this experiment using a $35-\mathrm{mm}$ all-sky camera (ASC) at Chatanika and 16-mm cameras at Ester Dome and Fort Yukon. Owing to excess light from the moon, the 16-mm photographs provided very little useful auroral information. Consequently, only the Chatanika ASC results are shown here. Rather than reproducing the ASC photographs directly, these data have been reduced to the auroral maps shown in Figure 5, for which an emission height of $110 \mathrm{~km}$ has been assumed. From these auroral maps it is apparent that the third range gate was substantially to the north of

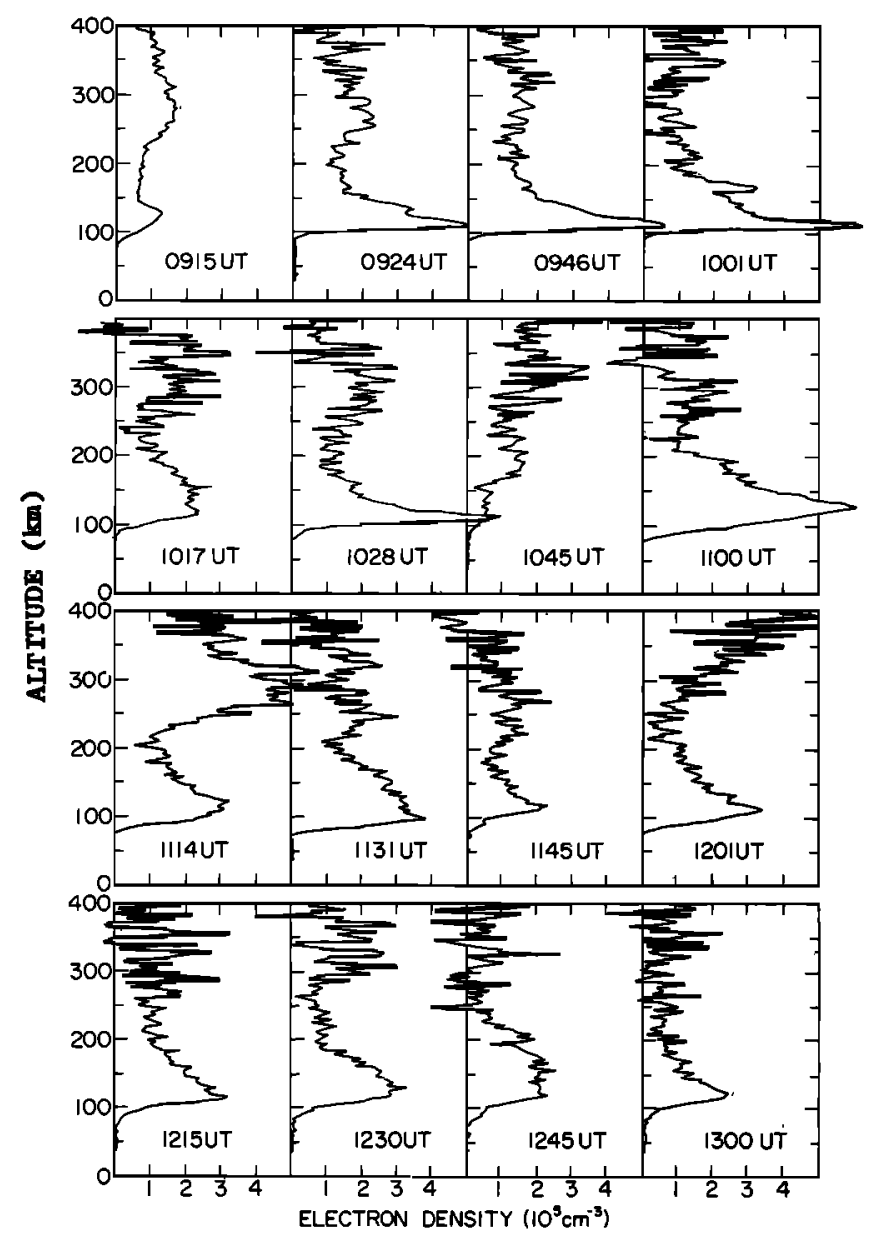

Fig. 7. Selected 1-min average electron density profiles as a function of altitude.

most visible auroral activity. Consequently, the observed electric fields can probably be characterized as those belonging to the poleward side of the auroral oval or perhaps even the outer edge of the polar cap.

A plot of the westward electric field component $\left(E_{w}\right)$ inferred from 1-min averages of the third range gate ion velocity is shown in Figure 6. At the top of this figure are also shown the 1-min average signal to noise ratio (SNR) estimates for the third range gate. Since the SNR is proportional to electron density averaged over the entire spectral range gate, it provides a convenient reference to the spectral channel average electron density as a function of time.

Figure 6 shows that the east-west electric field component was almost completely westward during the entire observational period, the values ranging between -10 and +35 $\mathrm{mV} \mathrm{m}^{-1}$. Although there is some randomness to consecutive data points, the 1-min data averaging period appears to have been sufficiently short to resolve many short-term fluctuations of the electric field. There does not seem to be any unique feature in $E_{w}$ before the 1100 UT substorm but, as Figure 3 shows, the series of disturbances began as early as $0840 \mathrm{UT}$, and the enhanced values of $E_{w}$ reflect a high degree of activity for the College area.

In Figure 7 short pulse electron density profiles are shown for different times during this experiment. Auroral $E$ and $F$ layers are clearly evident but, owing to spatial effects, it is not possible to consider these data as giving 


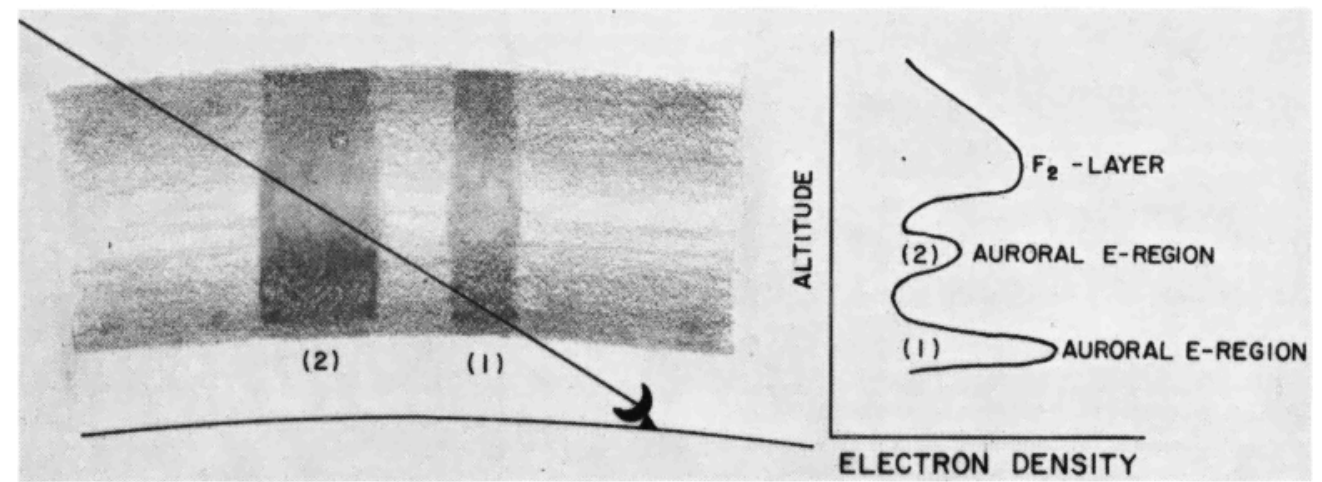

Fig. 8. Schematic diagram of the electron density range profile obtained in a spatially inhomogeneous ionosphere. The furthest density enhancement is intended to be the most intense, but owing to the way auroral ionization is distributed with altitude it appears less dense than the smaller enhancement seen in the $E$ region.

true altitude profiles, since horizontal variations are frequently important: The profile obtained at $1001 \mathrm{UT}$, for example, shows not only an auroral $E$ layer at $110 \mathrm{~km}$, but also a higher-altitude slice of an auroral feature $165 \mathrm{~km}$ north of Chatanika. To demonstrate this effect, a schematic diagram of the profile that results when several separate regions of enhanced auroral ionization are present is given in Figure 8.

\section{Results}

Anticorrelation of the westward electric field component and the electron density. Comparison of the results for $E_{w}$ and the third range gate $(167 \mathrm{~km})$ SNR (see Figure 6) shows that there is often a tendency for an inverse correlation. Clear examples of this are seen at 1009, 1021, 1055, and $1248 \mathrm{UT}$ and especially in the period after $1137 \mathrm{UT}$, when a large decrease in SNR was accompanied by a substantial increase in $E_{x}$. Likewise, periods of enhanced SNR (or electron density) were associated with significantly smaller values for $E_{w}$, the most notable occurrerices being found near 1100 UT and 1115-1137 UT. At other times the trend toward an inverse relationship seems to be present in competition 'with other processes. The rise in $E_{w}$ between 1100 and $1115 \mathrm{UT}$, for example, occurs during a time when the SNR is lower than during the preceding period of time, but whereas $E_{w}$ reaches about the same magnitude as was seen at $1050 \mathrm{UT}$, the SNR is several times greater.

The connection between electric fields and electron density involves currents in the $E$ region. Mozer et al. [1973], for example, have found that $E_{w}$ is greatly reduced above regions where the electrical conductivity is enhanced by auroral precipitation. One difficulty in studying the relationship between electric fields and electrical conductivity variations in the present experiment lies in the need to determine the $E$ region electron densities in the regions lying immediately below the third range gate. Anticorrelations between $E_{w}$ and the third range gate SNR need not always occur, however, since an enhanced auroral $E$ layer will not neeessarily be seen as a proportionate enhancement in the electron density at $167 \mathrm{~km}$.

An alternative way of investigating $E$ region effects upon $E_{\text {v }}$ involves the short-pulse observations of the auroral $E$ layer. Although the portion of the auroral $E$ layer sampled by the short-pulse method is about $50 \mathrm{~km}$ south of the region of the ionosphere sampled by the third range gate (see Figure 1 and the typical short-pulse range profiles in
Figure 7), the rapid southward drift of the ionization sources observed during this experiment (discussed in the next sectioni) implies that these lower-altitude densities may at times be useful to investigate the inverse electric field to electron density relationship. To show this, scalings of the peak $E$ region densities from the short-pulse data, have been included in Figure 6. As can be seen, there are a number of specific cases $(1009,1021,1055,1137,1248$ UT) when the inverse relationship seems to be present, especially when a 2-min delay time is introduced in the auroral $E$ layer data to account for the southward drift of the ionization source.

It must also be pointed out, however, that $E_{w}$ and the $E$ region electron density may not be strictly anticorrelated. Though a number of measurements [Aggson, 1969; Heppner et al., 1971; Potter and Cahill, 1969; Wescott et al., 1970; Potter, 1970] indicate a marked tendency for $\mathbf{E}_{\perp}$ to be lower in the vicinity of aurora, other observations [Mozer and Bruston, 1967; Kelley et al., 1971a, b; and Choy et al., 1971] show no anticorrelation. More recent comparisons between $E_{\perp}$ and auroral $\mathbf{X}$ ray and optical emissions have been made by Mozer et al. [1973]. These authors find a strong anticorrelation between $E_{w}$ and electron precipitation; i.e., the result suggested by the present data. From their experiments

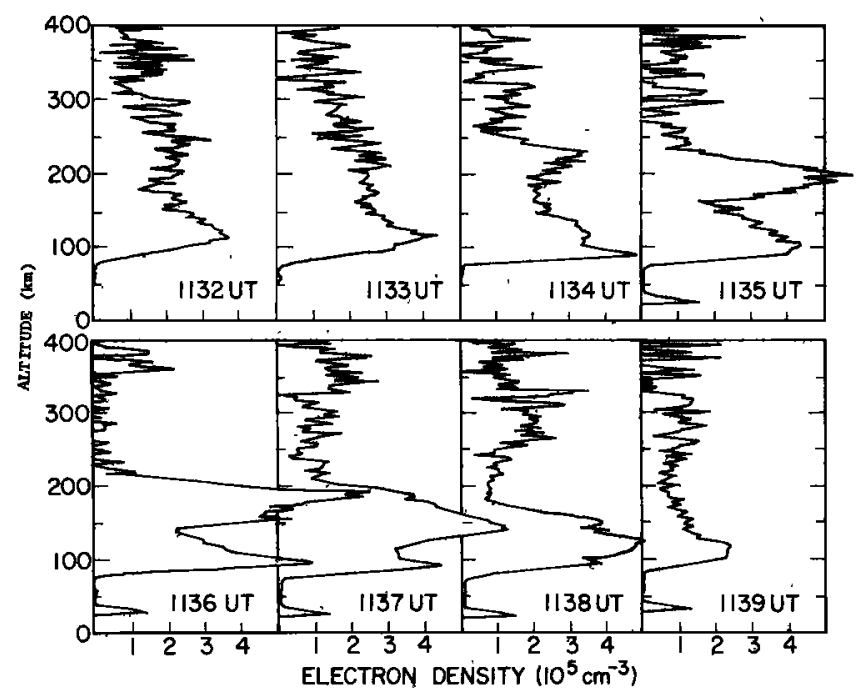

Fig. 9. Electron density profiles obtained for the period 1133 to 1138 UT showing the southward movement of a dense, thick wall of ionization. As the wall passes through the 115km height (or horizontal range) there is no large enhancement of the $E$ layer. 


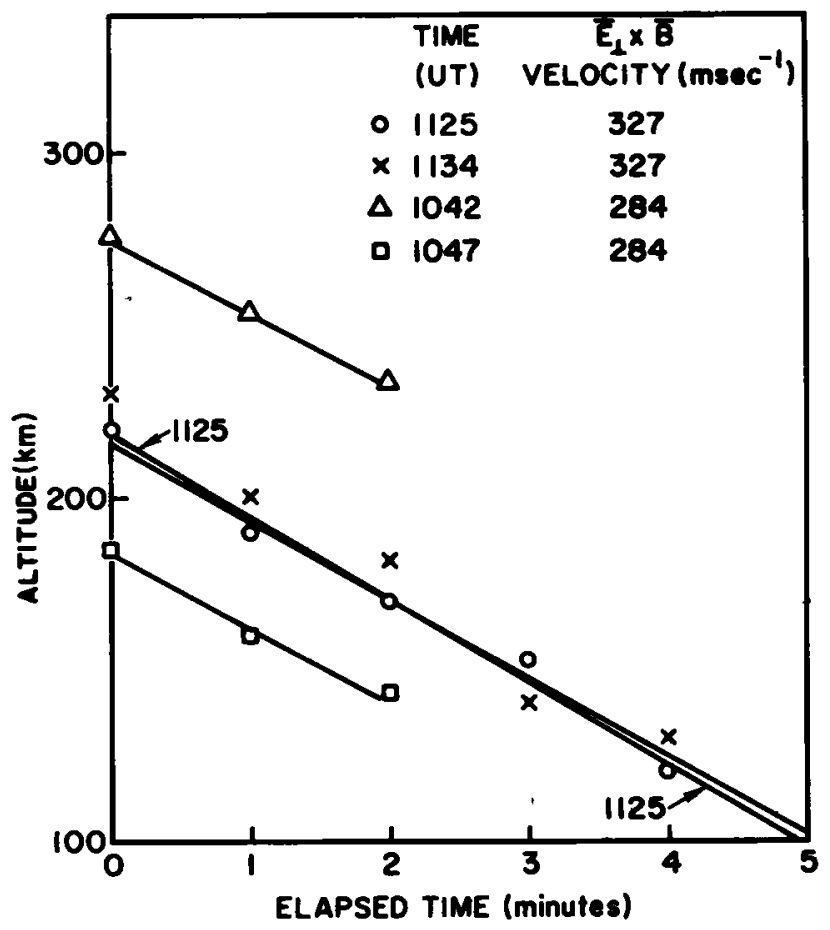

Fig. 10. Apparent altitude of electron density enhancements as a function of elapsed time.

decreases in $E_{w}$ were found during precipitation events about $70 \%$ of the time.

Motions of auroral ionization enhancements. Analysis of the short-pulse electron density data shows that large bands (up to $50 \mathrm{~km}$ wide and $100 \mathrm{~km}$ high) of enhanced electron density had apparent southward drift speeds that were about the same as the average plasma speed outside the enhanced density regions. From the discussion of the last section, however, the velocity of the plasma inside the moving density enhancements was usually substantially smaller than that outside.

The best example of this behavior is found in the period 1134 to 1138 UT, when an extended region of enhanced electron density appeared to move southward toward Chatanika. This motion is shown in Figure 9, where density profiles are shown for several consecutive data integration periods. This ionization enhancement was first seen at an apparent height of $225 \mathrm{~km}$. As time passed the high-density region appeared to move toward Chatanika, vanishing from view after 1138 UT. The southward component of drift velocity (perpendicular to B) was $327 \mathrm{~m} \mathrm{sec}^{-1}$ as determined by a least squares fit to the apparent altitude of the peak as a function of time (see Figure 10). This velocity corresponds to an equivalent electric field of $17 \mathrm{mV} \mathrm{m}^{-1}$, i.e., close to the 20 to $25 \mathrm{mV} \mathrm{m}^{-1}$ electric field seen immediately before and after the enhanced density region passed through the third range gate. During the time this region was within the third range gate, the inferred westward electric field was very small, indicating that, while the region itself was drifting, the plasma inside the enhanced region was not moving appreciably. A schematic diagram of this peculiar situation is given in Figure 11. In principle this behavior appears to agree with the recent model of Kelley et al. [1971b], where ionization sources are thought to undergo $\mathbf{E}_{\perp} \times \mathbf{B}$ drifts even though $E_{w}$ inside the region of enhanced density remains small.

Another important aspect of the 1134-1138 UT ionization region is seen in the abrupt increase in $E_{w}$ at the time that the third range gate SNR decreased (1138 UT) after the ionization region had passed. Through examination of the ion velocity data from range gates 4 through 7 , shown in Figure 12(a), it can be seen that the change of $E_{w}$ appeared to propagate southward toward Chatanika at a speed of $495 \mathrm{~m} \mathrm{sec}^{-1}$ (see Figure $12 b$ ). In this case it seems that the region of enhanced $E_{w}$ moved in conjunction with a boundary of greatly reduced precipitation and low $E$ region electron densities. This observation supports the idea of anticorrelation between $E_{w}$ and region conductivity. This abrupt transition and its implications are further discussed in the next section.

Finally, we must note that the ionization structure seen between 1134 and 1138 UT has been described in terms of a patch or band. Actually, the term 'ionization wall' would be more appropriate, since it is clear from Figure 9 that the density enhancement was at least $50 \mathrm{~km}$ wide and had an altitude extent of at least $100 \mathrm{~km}$; i.e., from the lower $F_{\mathrm{a}}$ region down to the $E$ region. It is within the horizontal confines of this wall that $E_{w}$ was substantially reduced in comparison with the external electric field. As is shown by the data of Figure 9, the wall itself underwent a rapid southward drift.

The detection of drifting ionization regions was not confined to postsubstorm (1100 UT) times. Such motions could be identified during virtually every 10 -min period between

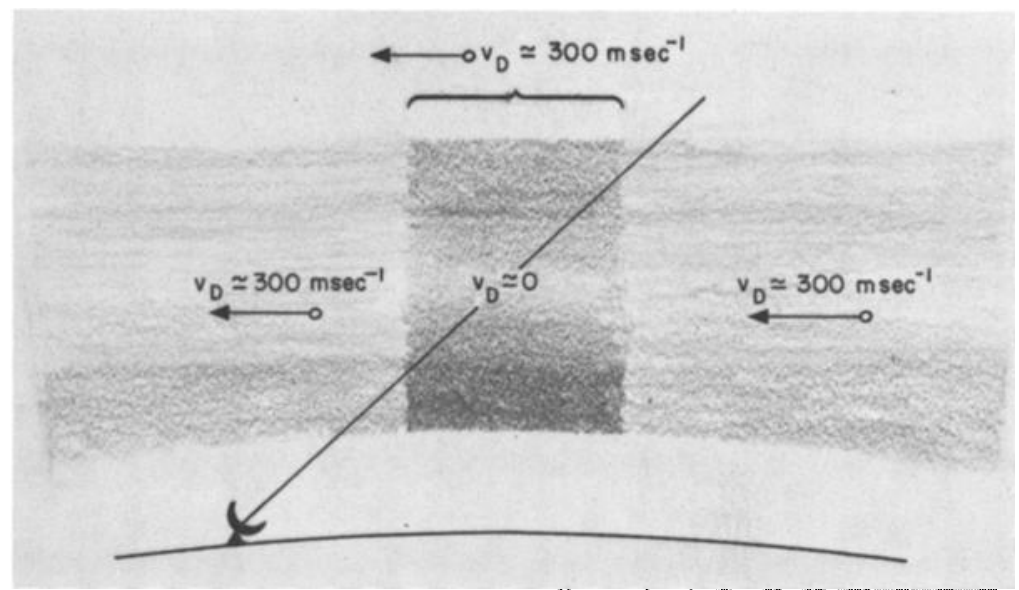

Fig. 11. Schematic illustration of the observed plasma drift velocities in the vicinity of a large density enhancement. 


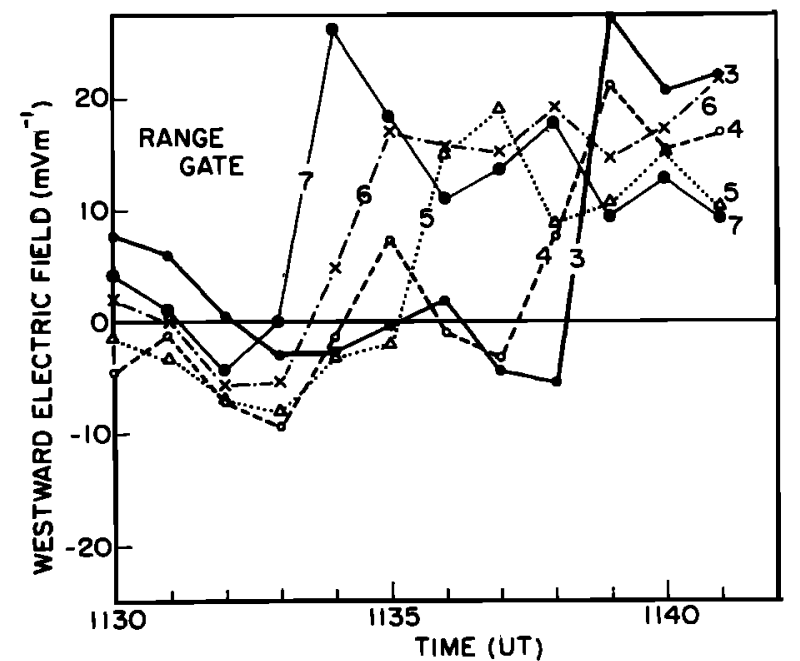

Fig. 12a. Westward electric fields obtained from range gates 3 through 7 as a function of time.

1000 and 1300 UT. Three additional examples of such drifts, included in Figure 10, show speeds of 284 and $337 \mathrm{~m} \mathrm{sec}^{-1}$. However, the corresponding condition of there being a smaller electric field within the enhanced ionization region could be definitely made only for ionization enhancements seen at 1015, 1100, 1117, and 1134-1137 UT.

Drifting regions of high ionization density and associated electrical currents are also found in the College magnetic records. As is shown in Figure 13, from 1050 to 1150 UT variations of $E_{w}$ were matched by similar amplitude variations in the magnetic $H$ and $D$ components. However, a time lag of about $5.5 \mathrm{~min}$ can be seen between the two quantities. Such a period corresponds to the time required for an ionization region to travel from the third range gate to the vicinity of College at a speed of about $350 \mathrm{~m} \mathrm{sec}$. This strongly implies that the structure of the westward electric field component between 1050 and 1150 UT was determined by the spatial distribution of the ionospheric electron densities moving past the third range gate and the College magnetic observatory.

The electron density enhancement seen between 1134 and $1138 \mathrm{UT}$ had an apparent southward speed of $327 \mathrm{~m} \mathrm{sec}^{-1}$.

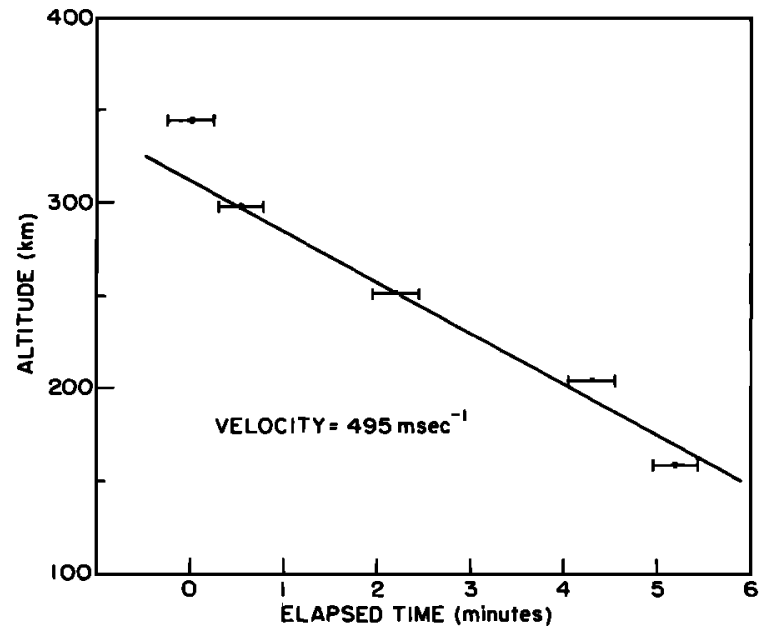

Fig. 12b. Altitude (or horizontal range) of the zero crossings of Figures $12 a$ as a function of time. The solid curve gives the least squares fit to the data. The error bars correspond to the 1-min averaging times.

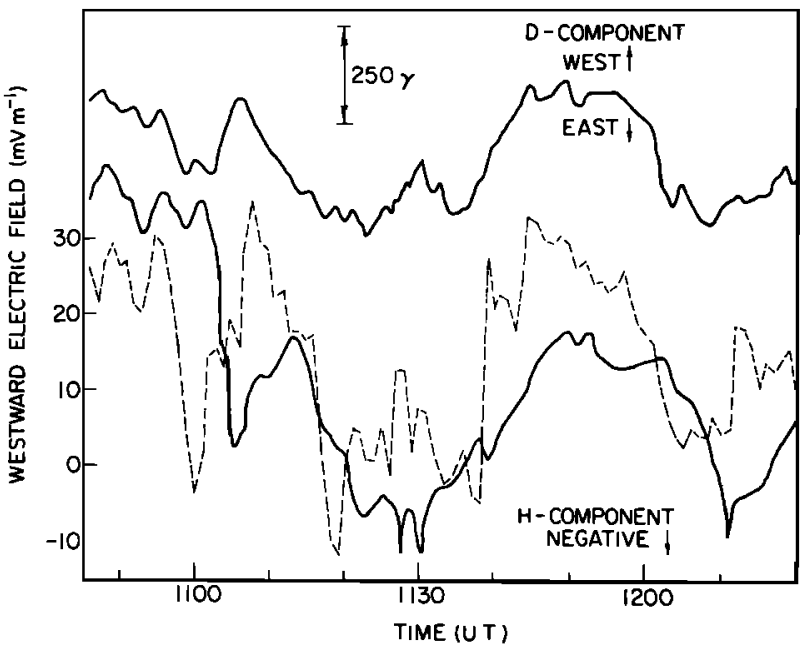

Fig. 13. Comparison of the westward electric field deduced from range gate 3 (dotted curve) and the College $H$ and $D$ components of the magnetic field (solid curves). The time delay of $5.5 \mathrm{~min}$ near $1100 \mathrm{UT}$ between $E_{\infty}$ and $H$ (and $D$ ) corresponds to a $350 \mathrm{~m} \mathrm{sec}-1$ southward motion for the region of electrical current flow.

Examination of the ASC records indicates that this enhancement corresponded to a diffuse rayed band seen at $1133 \mathrm{UT}$ and 1137 UT moving southward with an average speed of about $300 \mathrm{~m} \mathrm{sec}$. Owing to its faintness (which is a consequence of its motion), the width of this band cannot be determined from the ASC records. The radar, however, indicates precipitation over a $50-\mathrm{km}$-wide region. Enhancements seen earlier in the experiment cannot be readily identified with specific auroral forms. Examination of the ASC records in the period after $1100 \mathrm{UT}$, however, indicates a generally southeasterly motion of visible forms with speeds between 300 and $500 \mathrm{~m} \mathrm{sec} \mathrm{s}^{-1}$. After $1138 \mathrm{UT}$ it was difficult to find any auroral emissions in the ASC records. Photometer observations of $6300 \mathrm{~A}$ emissions in a $5^{\circ}$ cone at the Chatanika zenith show clearly the passage of a 5-kR or greater emission feature associated with the 11331137 U'T diffuse rayed band. The time of appearance of this emission feature was in good agreement with the radarobserved drift speed of the $E$ region density enhancement.

Before passing to the next topic, we note that the motion of auroral ionization creates a special observational problem for the analysis of the radar data. To obtain respectable electron density range profiles, it is necessary to timeaverage the scattered radar signal. However, a moving ionization band will remain in a particular range gate only for a short time. At $400 \mathrm{~m} \mathrm{sec}{ }^{-1}$, for example, a narrow ionization band passes through a $10 \mathrm{~km}$ wide gate in 25 sec. Thus, though one would like to integrate the electron density data only over the time it takes the ionization band to pass through the range gate, the statistical nature of the radar signal requires longer times to obtain good signal-tonoise ratios for the background plasma in adjacent ranges.

Electron densities. A substantial auroral $E$ layer was present during most of this experiment. The density variation of this peak has been shown in Figure 6 and is repeated in Figure 14 in conjunction with the observed variation of the apparent height of the maximum electron density. The uncertainty surrounding the true height of the peak density is unfortunate, but by looking at general trends and remembering that there is considerable evidence for south- 


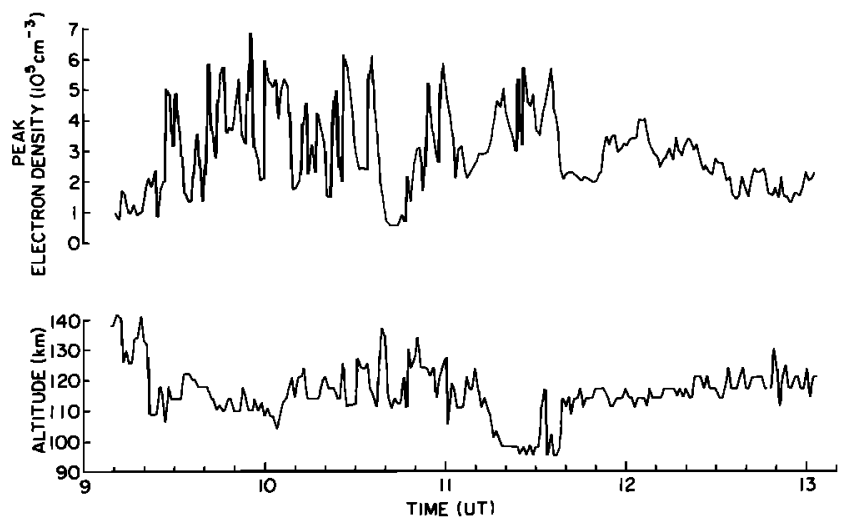

Fig. 14. The measured variation in the peak auroral $E$ layer electron density is shown as a function of time in the upper plot. The apparent height of the layer is shown below.

ward motion of the ionization regions, we can get some average notion about changes in the height of the $E$ layer.

During the first $2 \frac{1}{2}$ hours of the experiment the auroral $E$ layer was highly structured as new forms continually appeared or intensified in the radar line of sight. A pronounced minimum in electron density near 1038 UT was followed by a gradual increase marked by substantial variations. From ASC records (see Figure 5), there was a sharp brightening of auroral forms first seen at 1042 UT which could have signaled the onset of a substorm. However, there is no evidence for subsequent expansion and breakup phases, and so this brightening cannot be regarded as more than a period of enhanced magnetospheric activity.

Comparison of Figures 14 and 4 shows that the intense negative bay observed at 1100 at College was not associated with any special intensification of the particle flux or hardening of the energy spectrum at the radar $E$ layer penetration region $110 \mathrm{~km}$ north of College. In fact, the only unusual change seemed to center in the period 1110 to 1138 UT when, as deduced from the decreased altitude of the auroral $E$ layer, the energy of the precipitating electrons increased greatly. Use of the electron flux/energy nomographs given by Chesnut et al. [1971] suggests that the electron densities observed at this time could have been produced by an electron flux of $\sim 5 \times 10^{x}$ electrons $\mathrm{cm}^{-2}$ sec $^{-1}$ ster $^{-1}$ having a mean energy of $\sim 25 \mathrm{keV}$. The auroral forms detected by the ASC and shown in Figure 5 suggest that the transition to a hard electron flux was associated with auroral breakup and the passage of a westward surge through the radar line of sight.

After 1138 UT there was a marked change in the character of the $E$ layer, with an abrupt transition to rather steady precipitation typical of $6-\mathrm{keV}$ electrons with a flux of $\sim 10^{8}$ electrons $\mathrm{cm}^{-2} \mathrm{sec}^{-1} \mathrm{ster}^{-1}$. As was discussed earlier, it was at this same time that $E_{w}$ showed what appears to be a related abrupt increase.

Another interesting feature of the present data is the behavior of the $F_{2}$ region near the time of the $1100 \mathrm{UT}$ negative bay. In Figure 15 profiles of 1 min averaged electron density show the growth of an abnormally large $F_{2}$ layer to the north of Chatanika in the period before 1100 UT. The observed densities are substantially larger than those normally observed by the radar [e.g., Watt, 1973; Bates et al., 1973]. From range gate 5 ion velocity data, this intense $F_{2}$ layer was moving southward at a velocity of $400 \mathrm{~m} \mathrm{sec}^{-1}$. Unlike the walls of enhanced ionization seen at lower altitudes, this region of enhanced density did not extend appreciably downward; i.e., the observed density was part of a moving layer rather than the upper part of an ionization anomaly.

Following the initial development of this enhanced $F_{2}$ layer, one finds that the ionization density remained rather steady until $1100 \mathrm{UT}$, when the $F_{\text {a }}$ region ionization dropped to very low values within $1 \mathrm{~min}$. During the next $15 \mathrm{~min}$ the $F_{\mathrm{a}}$ region recovered to some extent, perhaps in conjunction with the passage of the westward surge that followed the $1100 \mathrm{UT}$ substorm. The growth of this unusual $F_{2}$ layer coincided with the 1042 UT brightening of auroral ares (see Figure 5) and the general increase in the intensity of the auroral precipitation before 1100 UT.

At the present time it is necessary to regard the sudden appearance of a dense $F_{\mathrm{a}}$ layer just before the 1100 UT substorm onset as a coincidence. This behavior was not repeated during the February and March 1973 experiments (which are not reported here). However, the presence of anomalously large $F_{2}$ regions that frequently appeared and disappeared was noted during the large August 4-9, 1972, magnetic storm (M. Baron, personal communication, 1973).

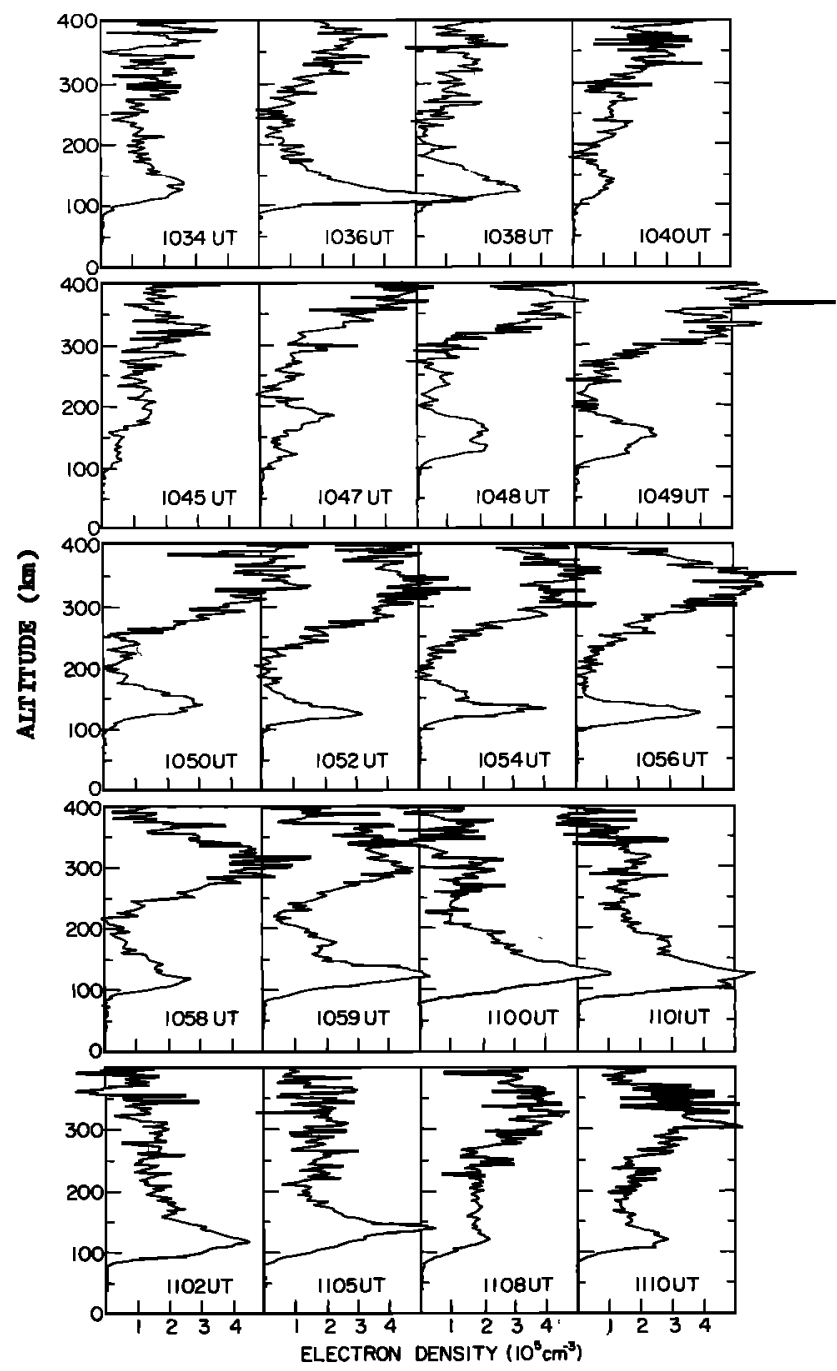

Fig. 15. Profiles of ionospheric density as a function of apparent altitude in the period 1034 to 1110 UT. The gradual growth of a dense $F_{2}$ region followed by its disappearance at 1100 UT is unusual. During this period the $F_{a}$ layer had a southward velocity of about $400 \mathrm{~m} \mathrm{sec}^{-1}$. 
Finally, although there is some slight indication that the equatorward edge of the dense $F_{2}$ layer was seen to propagate toward Chatanika (see Figures 7 and 15), it is not possible to identify particular southward-moving features such as was possible for the $E$ and $F_{1}$ region using range gate 3 and the short-pulse measurements of electron density.

Thermal structure. During this experiment measurements of electron and ion temperatures were obtained at $F$ region heights. The results, shown in Figure 16, were obtained with 10-min integration periods using techniques described by Baron [1972].

With regard to the electron temperature, the most striking feature occurred in the period 1040 to $1100 \mathrm{UT}$, when $T_{e}$ was $1400^{\circ} \mathrm{K}$ lower than temperatures measured before and after this time. This abrupt decrease appears to be closely linked with the previously described dense $F_{2}$ layer that moved into sight of the furthest radar range gates near 1040 UT. Since the electron to ion energy transfer rate is proportional to $n_{s}{ }^{2}$, the high values of $n_{\theta}$ in the enhanced $F_{\text {a }}$ layer should, as observed, lead to a substantial reduction in $T_{\text {. }}$.

The present values of $T_{\varepsilon}$ at $300 \mathrm{~km}$ tend to be substantially higher $\left(500^{\circ}-1000^{\circ} \mathrm{K}\right)$ than those recently reported by Bering et al. [1973] from a Langmuir probe rocket measurement. However, the extensive incoherent scatter radar measurements of temperatures and electron densities described by Watt [1973] indicate a wide variability in $T_{\text {。 }}$ during periods of auroral activity. Thus there is no particular significance to the difference between rocket and radar observations.

Two ion temperature curves are shown in Figure 16 corresponding to 211 and $300 \mathrm{~km}$ altitude. No features similar to those seen for $T_{e}$ are present, but there is a marked tendency for $T_{1}$ to increase up through 1130 UT to values near $1600^{\circ} \mathrm{K}$ at $300 \mathrm{~km}$ altitude. Normally, values of $T_{i}$ at $300 \mathrm{~km}$ reflect the neutral gas temperature. However, owing to the effects of Joule heating associated with large relative bulk flow velocities between the ions and neutral gas, this condition is probably not true in the present case.

\section{Discussion}

The results of this experiment provide both confirmation for a number of processes previously detected in the auroral ionosphere and evidence for several new features.

The relationship between westward electric fields and the motion of auroras has been studied by Kelley et al. [1971b], Davis [1971], and Subbarao and Rostoker [1973]. In agreement with these earlier measurements, this experiment shows that the southward motion of auroral ionization enhancements can, within the accuracy of the present technique, take place at the $E_{\perp} \times B$ drift velocity. In one specific instance (1134 to $1138 \mathrm{UT}$ ), it was also observed that the plasma within the moving region of enhanced density was virtually stationary with respect to the radar. The observation that drifting density enhancements are connected with lower values of $E_{w}$ agrees with the discussion of Kelley et al. [1971b] and Mozer et al. [1973] and indicates that, at times, the magnetospheric source of auroral electrons may move under the action of an $\mathbf{E}_{\perp} \times \mathbf{B}$ drift even though the ionospheric $E_{w}$ is rather small.

The most striking anticorrelation of electron density and $E_{\text {w }}$ occurred at $1138 \mathrm{UT}$ when abrupt sequential increases

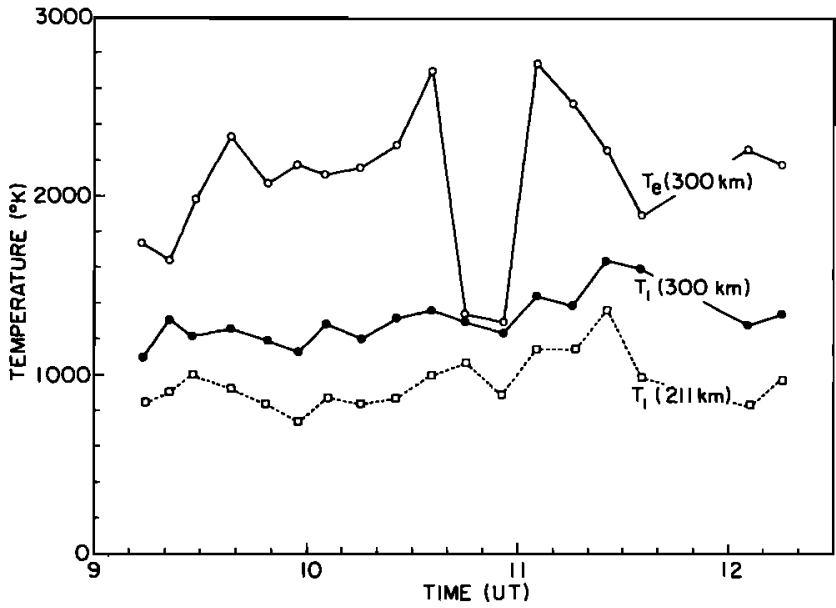

Fig. 16. Measured values of electron and ion temperature during the experiment. The large dip in $T_{s}$ at $300 \mathrm{~km}$ is a consequence of the large $F_{2}$ layer shown in Figure 15 .

in ion velocity were seen in the five spectral range gates beginning at the furthest range (see Figure 12a). During this same period, ASC and $E$ region density data show that there was a transition from intense, rapidly fluctuating precipitation to a much smoother, uniform behavior. From the last section, our interpretation of this period is that the rise in $E_{w}$ corresponded to the southward passage of a precipitation boundary that eventually left Chatanika in a region of relatively low electron density. However, it is necessary to point out that there is a completely separate explanation which, if verified in later experiments, could lead to a radically different view.

This second interpretation of the events that began at 1134 UT begins by assuming that the density enhancement seen in Figure 9 could be moving downward into the ionosphere. Similarly, the rise in $E_{w}$, which was previously assumed to move north to south, could actually have been associated with a downward-moving spatially extended boundary. If this were true one might be tempted to think that the downward-moving density enhancement and subsequent rise of $E_{v}$ were associated with field-aligned electric fields and anomalous resistivities such that when the density increase reached the upper $E$ region the electron precipitation weakened in intensity and average energy and was finally stopped. At this time the magnetospheric electric field could have penetrated to the lower parts of the ionosphere with its full magnitude.

The second interpretation could lead to an explanation of the previously noted anomaly in Figure 9 where no dramatic increase in electron density could be associated with the passage of the density enhancement through the $E$ region. Such a behavior would be expected if the density enhancement corresponded to some type of plasma accumulation layer rather than a precipitation zone. Likewise, the changes in the $E$ region peak density and altitude might correspond to a weakening of the electron acceleration process.

It must be realized that many aspects of the second interpretation are based upon conjecture. In addition, both the ASC observations of a diffuse band moving in conjunction with the electron density enhancement and the Chatanika zenith observations of $6300 \AA$ argue strongly in favor of the southward-moving wall idea rather than the downward- 
moving layer. Nevertheless, the layer interpretation cannot be completely discredited on the basis of the present data, and future experiments will be needed to completely determine the true spatial development.

If we accept the idea that the observed density enhancements were moving southward, the two-dimensional structure (thickness and height) introduces interesting questions about their origin and shape. The radar data indicate that the enhancements extended vertically to about $200 \mathrm{~km}$ altitude and that this plasma drifted southward at a fairly uniform speed (see Figure 10). However, it is puzaling that these enhancements do not seem to be simply regions of strong particle precipitation, since as they pass through the $110-$ to $120-\mathrm{km}$ region there is no apparent proportionate increase in the peak auroral $E$-region electron density. Thus the main part of the enhancement seems to be in the densities between 130 and $200 \mathrm{~km}$. Such higher densities could be associated with increases in the lower-energy portions of the electron energy spectrum and could perhaps explain why it was difficult to match the ASC auroral results to the southward-moving high-density regions.

The behavior of the intense $F_{\mathrm{g}}$ layer seen before the 1100 UT substorm onset appears to be anomalous. Yet, for this particular case, the rapid disappearance of the $F_{\mathrm{s}}$ layer presents a considerable puzzle. If this layer was simply an isolated patch, its disappearance could have been related to horizontal transport associated with the presence of a strong southward electric field at substorm onset; i.e., it moved rapidly southeastward and a new low-density $F_{\text {, }}$ region moved into the radar line of sight from the northwest. It could also be postulated that vertical motions were involved, moving the excess ionization either upward into the topside ionosphere or downward into the lower ionosphere. However, such motions would involve moving the plasma a distance of at least $100 \mathrm{~km}$ within $60 \mathrm{sec}$, corresponding to parallel speed of $1.6 \mathrm{~km} \mathrm{sec}$ or corresponding line of sight speed of $800 \mathrm{~m} \mathrm{sec}^{-1}$. Since such high speeds were not observed, it seems that the peculiar $F_{\mathrm{a}}$ layer was analogous to a drifting cloud that entered into the radar beam and vanished when the southeastward ion drift speed was suddenly increased.

\section{SUMMarY}

In summary, data from the Chatanika incoherent scatter radar have provided a comprehensive view of electric field and plasma variations in the auroral environment. Thepresent experiment confirms the tendency toward reduced values of the westward electric field in regions of higher than average electron density. Secondly, through observations of the electron density enhancements, these regions were seen to drift at approximately the $\mathbf{E}_{\perp} \times \mathbf{B}$ speed. The plasma inside these enhanced density regions, however, was found to move much more slowly than the surrounding ionization. The thermal structure of these regions did not show any unusual behavior; i.e., the low values of electron temperature are consistent with the electron to ion energy transfer rate which is proportional to $n_{\mathrm{e}}{ }^{2}$. Finally, although the present measurements were made during a period of continual magnetospheric disturbance, the variations in the westward electric field appeared to be more strongly linked with local electron density changes than with the overall disturbance pattern deduced from auroral zone magnetograms.
Acknowledgments. The assistance and comments of Drs. J. R. Doupnik, M. Baron, and S.-I. Akasofu are greatly appreciated. The all-sky camera reductions were made by Mr. D. S. Kimball.

This work was supported, in part, through NASA grant NGR-05-009-075 and NSF grant GA-36281 at the University of California, San Diego; NSF grants GA-30351, GA-28042, and GA-32590X at Stanford University; and NSF grant GA-36095 and DNA contract DNA-001-72-C-0076 at Stanford Research Institute.

The Editor thanks T. N. Davis and J. V. Evans for their assistance in evaluating this paper.

\section{REHERENCES}

Aggson, T. L., Probe measurements of electric fields in space, Atmospheric Emissions, edited by B. M. McCormac and A. Omholt, p. 305, Van Nostrand Reinhold, New York, 1969.

Axford, W. I., Magnetospheric convection, Rev. Geophys. Space Phys., $7,421,1969$.

Banks, P. M., J. R. Doupnik, and S.-I. Akasofu, Electric field observations by incoherent scatter radar in the auroral zone, J. Geophys. Res., 78, 6607, 1973.

Baron, M. J., DNA project 617 radar: Auroral ionospheric measurements, Rep. DNAS029F, Stanford Res. Inst., Menlo Park, Calif., December 1972.

Baron, M. J., O. de la Beaujardiere, and B. Craig, Project 617 radar readiness achievement program, $A$, Data processing and analysis, Rep. 2519-1, Stanford Res. Inst., Menlo Park, Calif., May 1970.

Bates, H. F., A. E. Belon, and R. D. Hunsucker, Aurora and the poleward edge of the main ionospheric trough, J. Geophys. Res., 78, 648, 1973.

Bering, E. A., M. C. Kelley, and F. S. Mozer, Split Langmuir probe measurements of current density and electric fieldo in an aurora, J. Geophys. Res., 78, 2201, 1973.

Brekke, A., J. R. Doupnik, and P. M. Banks, A preliminary study of the neutral wind in the auroral $E$ region, J. Geophys. Res., 78, 8235, 1973.

Cauffman, D. P., and D. A. Gurnett, Double-probe measurements of convection electric fields with the Injun 5 satellite, J. Geophys. Re8., 76, 6014, 1971.

Chesnut, W. G., J. C. Hodges, and R. L. Leadabrand, Correlation of radar echoes from the aurora with satellitemeasured particle precipitation, Rep. DNA-2825F, Stanford Res. Inst., Menlo Park, Calif., December 1971.

Choy, L. W., R. L. Arnoldy, W. Potter, P. Kintner, and L. J. Cahill, Field-aligned particle currents near an auroral arc, J. Geophys. Res., 76, 8279, 1971.

Davis, T. N., Magnetospheric convection pattern inferred from magnetic disturbances and auroral motions, J. Geophys. Res., 76, 5978, 1971.

Doupnik, J. R., P. M. Banks, M. J. Baron, C. L. Rino, and J. Petriceks, Direct measurements of plasma drift velocities at high magnetic latitudes, J. Geophys. Res., 77, 4268, 1972.

Evans, J. V., Theory and practice of ionosphere study by Thomson scatter radar, Proo. IEEE , 67, 496, 1969.

Evans, J. V., Ionospheric movements measured by incoherent scatter: A review, J. Atmos. Terr. Phys., 34, 175, 1972.

Fahleson, U., C. G. Falthammar, A. Pederson, K. Knott, G. Brommundt, G. Schumann, G. Haerendel, and E. Rieger, Simultaneous electric field measurements made in the auroral ionosphere by using three independent techniques, Radio Sci., 6, 233, 1971.

Föppl, H., G. Haerendel, L. Haser, R. Lüst, F. Meløner, B. Meyer, N. Neuss, H. H. Rabben, E. Rieger, J. Stöcker, and W. Stoffregen, Preliminary results of electric field measurements in the auroral zone, J. Geophys. Res., 73, 21, 1968.

Galperin, Yu. I., and V. N. Ponomarev, Direct measurements of plasma convection in the upper ionosphere, Rep. 130, Acad. of Sci. of the USSR, Inst. for Space Res., Moscow, 1972.

Haerendel, G., Electric fields and their effects in the ionosphere, Solar Terrestrial Physics, edited by E. R. Dyer, p. 87, D. Reidel, Dordrecht, Netherlands, 1972. 
Haerendel, G., and R. Lüst, Electric fields in the ionosphere and magnetosphere, Particles and Fields in the Magnetosphere, edited by B. M. McCormac, p. 213, D. Reidel, Dordrecht, Netherlands, 1970.

Haerendel, G., R. Lüst, E. Rieger, and H. Völk, Highly irregular artificial plasma clouds in the auroral zone, in Atmospheric Emissions, edited by B. M. McCormac and A. Omholt, p. 293, Van Nostrand Reinhold, New York, 1969.

Heppner, J. P., Electric fields in the magnetosphere, in Critical Problems of Magnetospheric Physics, edited by E. R. Dyer, National Academy of Sciences, Washington, D.C., 1972.

Heppner, J. P., J. D. Stolarik, and E. M. Wescott, Electricfield measurements and the identification of currents causing magnetic disturbances in the polar cap, J. Geophys. Res., $76,6028,1971$.

Kelley, M. C., F. S. Mozer, and U. V. Fahleson, Electric fields in the nighttime and daytime auroral zone, J. Geophys. Res., 76, 6054, 1971a.

Kelley, M. C., J. A. Starr, and F. S. Mozer, Relationship between magnetospheric electric fields and the motion of auroral forms, J. Geophys. Res., 76, 5269, $1971 b$.

Leadabrand, R. L., M. J. Baron, J. Petriceks, and H. F. Bates, Chatanika, Alaska, auroral zone incoherent scatter facility, Radio Sci., $7,747,1972$.

Mozer, F. S., Origin and effects of electric fields during isolated magnetospheric substorms, J. Geophys. Res., 76, $7595,1971$.

Mozer, F. S., and P. Bruston, Electric field measurements in the auroral ionosphere, J. Geophys. Res., 72, 1109, 1967.

Mozer, F. S., and U. V. Fahleson, Parallel and perpendicular electric fields in an aurora, Planet. Space Sci., 18, 1563, 1970.

Mozer, F. S., and R. H. Manka, Magnetospheric electric field properties deduced from simultaneous balloon flights, J. Geophys. Res., 76, 1697, 1971.
Mozer, F. S., and R. Serlin, Magnetospheric electric field measurements with balloons, J. Geophys. Res., 74, 4739, 1969.

Mozer, F. S., F. H. Bogott, and B. Tsurutani, Relations between ionospheric electric fields and energetic trapped and precipitating electrons, J. Geophys. Res., 78, 630, 1973.

Potter, W. E., Rocket measurements of auroral electric and magnetic fields, J. Geophys. Res., 75, 5415, 1970.

Potter, W. E., and L. J. Cahill, Electric and magnetic field measurements near an auroral electrojet, J. Geophys. Res., $74,5159,1969$

Rino, C. L., Radar measurement of ionosphere motion in the presence of current induced spectral asymmetries, Radio Sci., 7, 1049, 1972.

Rino, C. L., V. B. Wickwar, P. M. Banks, and S.-I. Akasofu, Incoherent scatter radar observations of westward electric fields, 2, submitted to J. Geophys. Res., 1973.

Subbarao, S., and G. Rostoker, The relationship of southward drifting auroral arcs to the magnetospheric electric field and substorm activity, J. Geophys. Res., 78, 1100, 1973.

Watt, T. M., Incoherent scatter observations of the ionosphere over Chatanika, Alaska, J. Geophys. Res., 78, 2992, 1973.

Wescott, E. M., J. D. Stolarik, and H. P. Heppner, Electric fields in the vicinity of auroral forms from motions of barium vapor releases, J. Geophys. Res., 74, 3469, 1969.

Wescott, E. M., J. D. Stolarik, and J. P. Heppner, Auroral and polar cap electric fields from barium releases, Particles and Fields in the Magnetosphere, edited by B. M. McCormac, p. 229, D. Reidel, Dordrecht, Netherlands, 1970.

(Received August 1, 1973

accepted September 14, 1973.) 